\title{
Phylogenetic Relationships of Species of the Genus Brachyrhaphis (Poeciliidae) Inferred from Partial Mitochondrial DNA Sequences
}

\author{
Camille L. Mojica, Axel Meyer, and George W. Barlow
}

\begin{abstract}
Phylogenetic relationships were reconstructed using partial mitochondrial DNA sequence data for the cytochrome $b$ gene among all nine described species of $\mathrm{Bra}$ chyrhaphis and several members of the tribe Gambusiini. We included three of the more than 40 members of the genus Gambusia and Belonesox belizanus, the third, monotypic genus of the tribe Gambusiini. Xiphophorus malinche served as the outgroup. Phylogenetic trees were generated using maximum-parsimony, maximumlikelihood, and neighbor-joining analyses. Hypotheses of relationships within the tribe and genus Brachyrhaphis made by previous authors were tested. The existence of a slim- and a deep-bodied clade within the monophyletic genus Brachyrhaphis was supported. Brachyrhaphis hartwegi is the basal member of the deep-bodied clade, whereas $B$. punctifer is the basal member of the slim-bodied clade.
\end{abstract}

$\mathrm{S}^{\mathrm{s}}$ PECIES of the genus Brachyrhaphis are found in freshwater streams, rivers, and swamps of Central America. The geographic distribution of Brachyrhaphis is disjunct; seven of the eight species are found in Costa Rica and Panama, whereas the eighth species, $B$. hartwegi, is found in Guatemala (Rosen and Bailey, 1963). These fishes are found at the shallow edges of bodies of water where they are able to feed on terrestrial insects that fall into the water (Bussing, 1988). The geographic ranges of individual species may overlap, but segregation seems to occur both by microhabitat and elevation. When found in the same area, one species usually occupies open streams, whereas the other inhabits swamps or backwater areas. Similarly, one species may replace another with increasing elevation in a given drainage.

Male poeciliid fishes are well known for their sexually dimorphic traits; these usually involve unique color patterns and elaborate morphology. Sex-specific differences range from vertical bars (Morris et al., 1995) and elongated "swords" (Basolo, 1995) to elaborate coloration in male guppies, Poecilia reticulata (Houde and Endler, 1990). Compelling evidence indicates that these traits have evolved via sexual selection (Houde and Endler, 1990; Endler, 1995). But in the genus Brachyrhaphis (and some Gambusia, e.g., G. sexradiata), these traits are found in both the males and females, making sexual selection via female choice unlikely explanations for the evolution of the female traits.

The novel morphology possessed by both sexes varies dramatically from the colorless and typical anal fin or gonopodium of Brachyrhaphis hartwegi, to the largely black anal fin/gonopodium of $B$. rhabdophora. Ornamentation of both male gonopodia and female anal fins are a unique condition within the family. Anal fins of females of some species are as colorful as the male gonopodia. Additionally, the black pigment is placed in such a way in the females of certain species that it traces the first three rays of the anal fin from their origin to the tip. This highlighted, lengthened region is about the same width as a male gonopodium. The fourth ray is lengthened in some species relative to the last rays of the anal fin, giving the fin a falcate shape.

The result of this combination of unique color patterns and morphology possessed by these females is that the anal fins bear a striking resemblance to the gonopodia of males of their own species. Both males and females use these fins during social interactions. The black area appears to change in intensity depending on social status (pers. obs.). This suggests that these structures function in social communication. The hypothesis, then, is that selection for communication has produced elaborate, colorful female anal fins that mimic the gonopodia of males. A phylogenetic tree is necessary to test this hypothesis because we will want to compare closely related species that vary in the expression of derived traits (Brooks and McLennan, 1991). Such a comparative study requires a phylogeny if it is to accommodate the potential nonindependence among data points. The morphology and color patterns will be more thoroughly described, and hypotheses concerning the adaptive significance of these traits will be tested elsewhere (CLM, unpubl.) using the phylogeny constructed here.

This investigation used mitochondrial DNA sequence data to resolve the phylogenetic relationships of the taxa mentioned. Such data have proven to be phylogenetically informative in 
many taxa (Meyer, 1994). Sequence data from the cytochrome $b$ gene have been particularly useful in resolving poeciliid systematics (Meyer and Lydeard, 1993; Lockhart et al., 1995; Lydeard et al., 1995).

Taxonomy.-Regan (1913) described the monotypic genus Brachyrhaphis (B. rhabdophora) based on the possession of a shorter gonopodium than that of Gambusia. The most thorough systematic study to date of the genus was based on morphology and is part of the revision of the family Poeciliidae by Rosen and Bailey (1963). They used similarities in male gonopodia to designate species. They included in the genus $\mathrm{Bra}$ chyrhaphis several species formerly assigned to Gambusia (G. cascajalensis, [Meek and Hildebrand, 1913]; G. episcopi [Steindachner, 1878]; G. parismina [Meek, 1912]; G. rhabdophora, Regan, 1908; G. terrabensis, Regan, 1907b). They also added $B$. punctifer (Trigonophallus punctifer [Hubbs, 1926]) to the genus and described $B$. hartwegi, a new species. Bussing later described two additional species to the genus $(B$. holdridg$e i, 1966$, and B. roseni, 1988).

Rosen and Bailey (1963) stated that a "particularly close relationship" between $B$. hartwegi and $B$. terrabensis existed based on the possession of a "bean-shaped fleshy pad near the tip of the first pelvic ray." Other close relationships were hypothesized when certain species $(B$. episcopi and $B$. terrabensis) were referred to as deep-bodied species and others (B. hartwegi, $B$. cascajalensis, and B. parismina) as slender-bodied species. They stated that $B$. cascajalensis "is most closely related to $B$. parismina."

The classification based on body depth was not used consistently, however, because they also referred to $B$. hartwegi as a slender-bodied species even though it was presumed to be closely related to the deep-bodied $B$. terrabensis. Having seen live specimens of every species, we describe $B$. hartwegi as a deep-bodied species. Rosen and Bailey (1963) did not discuss body depth when treating $B$. rhabdophora or $B$. punctifer, but we describe the former as a deep-bodied fish and the latter as a slender-bodied species. Brachyrhaphis holdridgei and B. roseni had not been described when Rosen and Bailey (1963) made their revisions. We believe both of these to be deep-bodied as well. An informal comparison of the body-depth data given in the original descriptions of all Brachyrhaphis species supports these ideas (unpubl. data).

Bussing (1988) hypothesized a close relationship between $B$. roseni and $B$. rhabdophora. Additionally, he included $B$. cascajalensis in $B$. parismina without providing an analysis of data to support this combination: "With the exception of $B$. parismina (including $B$. cascajalensis) the species of the genus also have a pattern of vertical black bars ..." (Bussing, 1988:81).

Brachyrhaphis holdridgei, B. roseni, B. rhabdopho$r a$, and $B$. punctifer resemble the deep-bodied $B$. episcopi and B. terrabensis in body depth and color pattern. All have black, orange, yellow, and/or red pigments accenting their fins; olivaceous bodies; and vertical bars along the flank. Brachyrhaphis cascajalensis and B. parismina lack these pigments, whereas $B$. hartwegi is yellow throughout.

Bussing (1988) stated that, when examining specimens of $B$. rhabdophora, he found additional differences between those occurring in northern Costa Rica and those in the south. The geographic boundaries thought to delimit the northern forms include Guanacaste and the Tarcoles drainage in central Costa Rica. The southern form is distributed from Punta Mala on the Nicoya Peninsula down to the Terraba drainage, where it is replaced by $B$. roseni $(\mathrm{W}$. A. Bussing, pers. comm.). Bussing does not comment on whether these species are each others' closest relatives.

Eight species currently make up the genus Brachyrhaphis that is part of the tribe Gambusiini. Members of the tribe also include the genus Gambusia, which contains more than 40 described species and the monotypic genus Belonesox. With respect to the tribe, Rosen and Bailey (1963) stated that Gambusia and Belonesox are most closely related to one another and that a form resembling $B$. cascajalensis gave rise to the ancestor of these two genera. The tribe was revised by Rauchenberger (1989). Her cladistic analysis of morphological data supported the previous notion that Gambusia and Belonesox are sister taxa.

Hypothesis testing.-The purpose of this study is to elucidate the relationships within the genus Brachyrhaphis and within the tribe Gambusiini so that the resultant phylogenetic tree can be used in addressing the evolution of novel morphology and behavior patterns. In producing a phylogenetic tree, we tested the hypotheses put forth or implied by previous investigators. These include the following: (1) Brachyrhaphis is a monophyletic genus with respect to other gambusiin fishes (Rauchenberger, 1989); (2) a deep-bodied clade consists of $B$. episcopi, B. holdridgei, $B$. rhabdophora, and $B$. terrabensis (Rosen and Bailey, 1963); (3) B. hartwegi and B. terrabensis are closely related (Rosen and Bailey, 1963); (4) B. cascajalensis and B. parismina comprise a slim-bodied clade, and/or the two latter 
described forms represent one species (Rosen and Bailey, 1963; Bussing, 1988); (5) B. holdridg$e i$ is more closely related to the slim-bodied clade than to the other species of the genus (Bussing, 1966); and (6) what is currently $B$. rhabdophora is a paraphyletic group of species (Bussing, 1988).

The last hypothesis refers to Bussing's assertion that $B$. rhabdophora should be split along geographic boundaries. This study cannot establish the existence of two species. Bussing's hypothesis can be supported, however, if the populations are found to be paraphyletic. This study will be inconclusive with respect to this hypothesis if monophyly is the result. Partial mitochondrial DNA sequences for the mitochondrial cytochrome $b$ gene were used in a phylogenetic analysis to construct a tree with which to test this and the other six hypotheses.

\section{MATERIALS AND METHODS}

Specimens.-All specimens of Brachyrhaphis were collected in the field or obtained from other collectors and sequenced by CLM. At least one individual per species was sequenced. Additional sequences from two species were acquired to reveal inter- and intrapopulation variation. Data from three individual B. episcopi were gathered: two from the same population (Barro Colorado Island, Panama) and one from a second population (Rio Mendoza, Pipeline Road, Panama). This study also included three representatives from the geographic range of $B$. rhabdophora: a northern type from the Rio Tenorio (Rio Bebdedero Drainage, Guanacaste Province, Costa Rica); a central form from Santa Ana (San Jose Province, Costa Rica); and a southern type from the Rio Angel (near San Isidro del General, San Jose Province, Costa Rica). The three specimens of Gambusia and one Belonesox were obtained and sequenced in AM's laboratory (Meyer and Lydeard, 1993; Lydeard et al., 1995). Voucher specimens of Brachyrhaphis were deposited at the California Academy of Sciences.

Sequence collection.-Conventional methods were used to obtain 12 of the 17 sequences via manual sequencing from a 350-base-pair (bp) region of the cytochrome $b$ gene of the mitochondrial genome (Kocher et al., 1989; Walsh et al., 1991; Smith and Patton, 1993). Five sequences were obtained via automated sequencing (Lydeard et al., 1995). Double-stranded products for five of the specimens (B. episcopi [B2], $B$. rhabdophora [S], Gambusia affinis, G. nicaraguensis, Belonesox belizanus, and Xiphophorus malinche) were used to acquire sequences via standard au- tomated sequencing protocols. The sequences obtained were deposited in GenBank.

Phylogenetic analysis.-All sequences were entered into PAUP, Vers. 3.1.1 for the Macintosh (Swofford, 1991, unpubl.), and aligned by eye. This program was used to perform a phylogenetic analysis using the principle of maximum parsimony (MP). The weighting scheme applied to the data followed the suggestions made by Meyer (1994) in his evaluation of cytochrome $b$ as a molecular marker.

The shortest tree was found in a heuristic search with tree bisection-reconnection (TBR) branch-swapping in 10 random-addition replicates. The MULPARS option was chosen (all minimal trees saved). Xiphophorus malinche was designated as the outgroup (Rosen and Bailey, 1963; Meyer and Lydeard, 1993). The integrity of the tree was measured by bootstrapping (Felsenstein, 1985) using a heuristic search as described above and 100 replicates.

Nodes within the tree were compared using the Decay Index (DI; B. D. Mishler, M. J. Donoghue, and V. A. Albert, unpubl.). The DI is the number of steps required to collapse a node in a parsimony analysis (B. D. Mishler, M. J. Donoghue, and V. A. Albert, unpubl. abstract). Successively longer trees were saved during PAUP's heuristic search. The strict consensus of the resultant trees revealed the nodes that had collapsed.

The software package PHYLIP (Felsenstein, 1989) was used to execute a second phylogenetic method, maximum likelihood (ML; Felsenstein, 1985), and a distance-based method, neighbor-joining (NJ; Saitou and Nei, 1987). Parameters specified in the maximum-likelihood analysis (DNAML) included one category of substitution, default parameters, and the designation of $X$. malinche as the outgroup. Tree robustness was inferred from $P$-values calculated for length of branches.

A Kimura two-parameter model (Kimura, 1980) was used in calculating a corrected distance matrix in the DNADIST subroutine and served as the input for the subroutine NEIGHBOR in PHYLIP. Tree robustness was assessed by bootstrapping. One hundred data sets were generated in SEQBOOT, distance matrices were calculated for each data set in DNADIST, the shortest tree for each was found in NEIGHBOR, and the consensus tree was generated by CONSENSE. These three sets of analyses were performed to test whether different results were produced by different phylogenetic methods. 


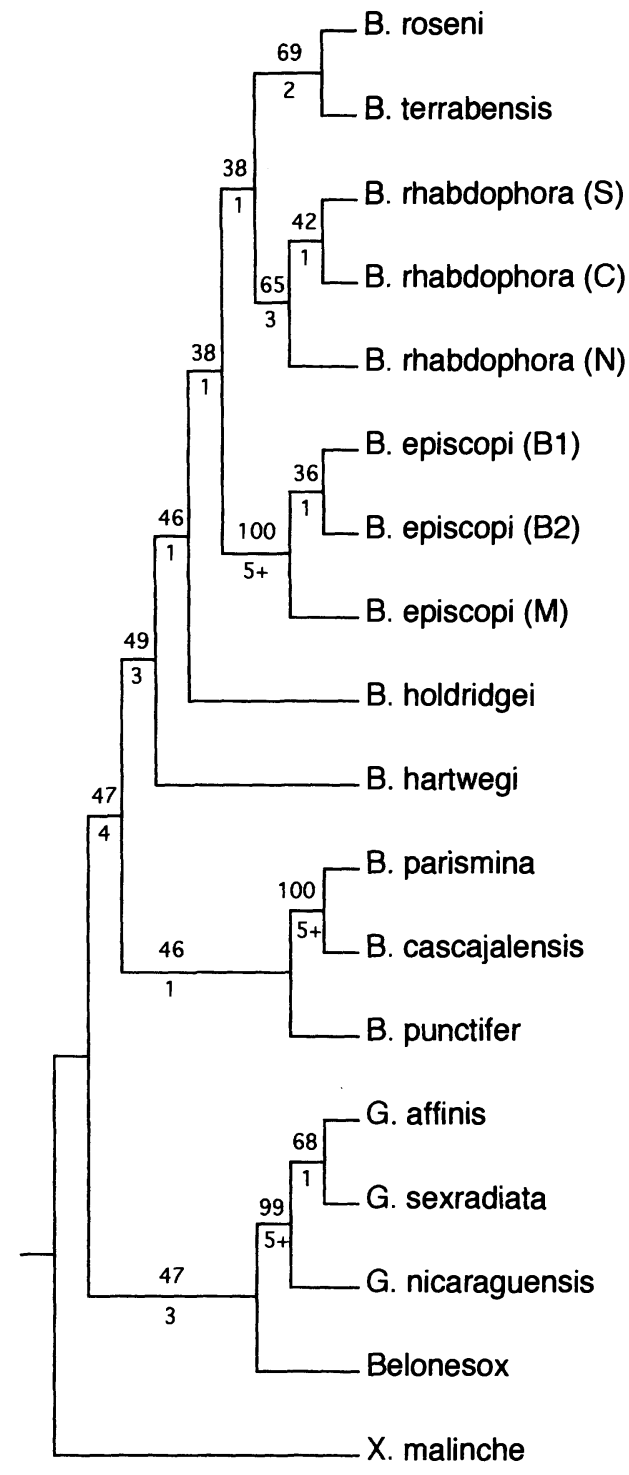

Fig. 1. Maximum-parsimony result. Consensus tree (50\% majority-rule) generated in PAUP 3.1.1 (Swofford, 1991, unpubl.). Decay indices are shown below, and bootstrap values (100 replicates) are shown above each internode. Specimens of Brachyrhaphis episcopi from Barro Colorado Island, Panama, are denoted B1 and B2. The specimen from the Rio Mendoza is labeled M. Specimens of $B$. rhabdophora from the southern, central, and northern parts of Costa Rica are labeled S, C, and N, respectively.

\section{RESUlts}

When these data were analyzed (GenBank accession U68300-12), three shortest trees were found via MP. The three trees differed only in the relationships among the three specimens of

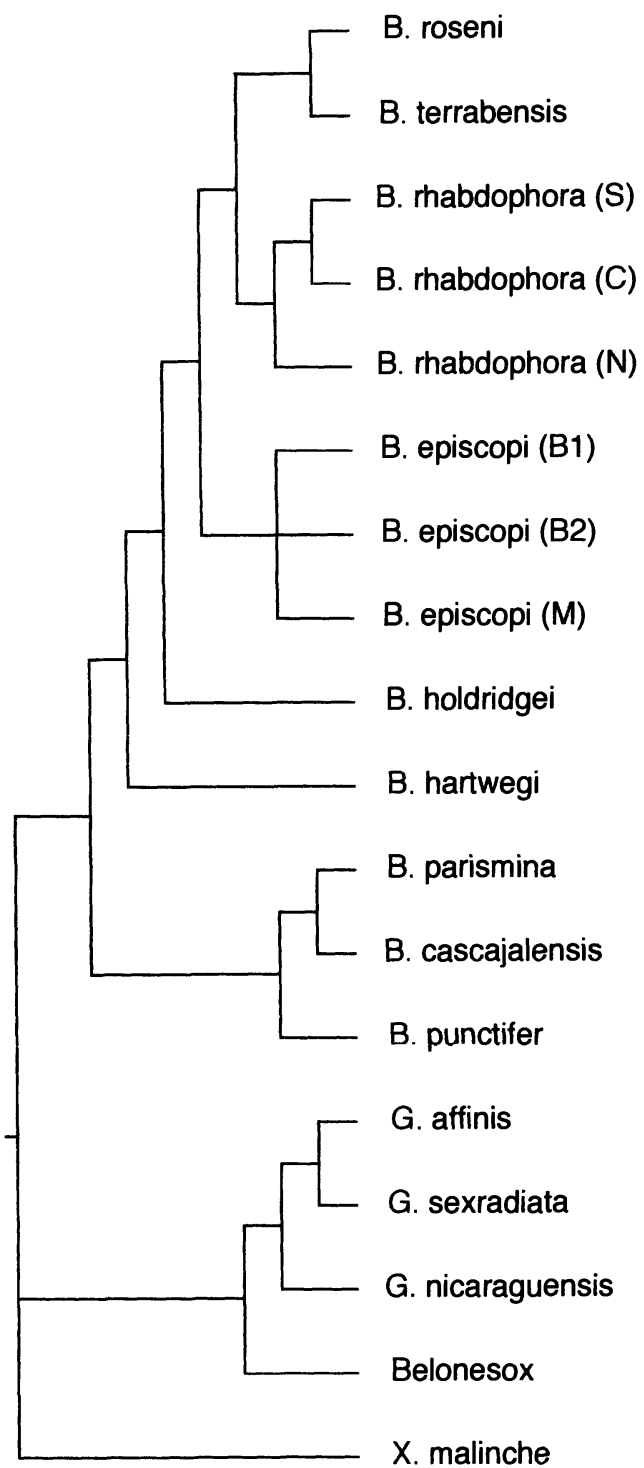

Fig. 2. Maximum-likelihood result. Tree generated in PHYLIP (Felsenstein, 1989). Nonsignificant branch lengths are collapsed. See Materials and Methods for parameters chosen. Specimens of Brachyrhaphis episcopi from Barro Colorado Island, Panama, are denoted B1 and B2. The specimen from the Rio Mendoza is labeled M. Specimens of B. rhabdophora from the southern, central, and northern parts of Costa Rica are labeled S, C, and N, respectively.

B. episcopi included in this study. The strict-consensus tree shown (Fig. 1) is 415 steps long. Bootstrap values and the DI are given at each node. Seventy-two phylogenetically informative characters were found out of the possible 381 . The consistency index for this tree is 0.567 . The log of the consistency index is negatively correlated with the number of taxa (Sanderson and 
Table 1. Lower-Triangle Distance Matrix Generated by DNADIST in PHYLIP (Felsenstein 1989). See Materials and Methods for parameters chosen. Specimens of (Brachyrhaphis episcopi from Barro Colorado Island, Panama, are denoted B1 and B2. The specimen from the Rio Mendoza is labeled M. Specimens of B. rhabdophora from the southern, central, and northern parts of Costa Rica are labeled S, C, and N, respectively.

\begin{tabular}{|c|c|c|c|c|c|c|c|c|c|}
\hline & 1 & 2 & 3 & 4 & 5 & 6 & 7 & 8 & 9 \\
\hline 1. B. roseni & * & & & & & & & & \\
\hline 2. B. episcopi $(\mathrm{BI})$ & 0.1259 & & & & & & & & \\
\hline 3. B. episcopi (B2) & 0.1266 & 0.0029 & & & & & & & \\
\hline 4. B. episcopi (M) & 0.1559 & 0.0266 & 0.0298 & & & & & & \\
\hline 5. $B$. holdridgei & 0.0843 & 0.1147 & 0.1153 & 0.1440 & & & & & \\
\hline 6. B. parismina & 0.1531 & 0.1954 & 0.1965 & 0.2295 & 0.1247 & & & & \\
\hline 7. B. terrabensis & 0.0351 & 0.1052 & 0.1058 & 0.1249 & 0.0802 & 0.1455 & & & \\
\hline 8. B. rhabdophora $(\mathrm{S})$ & 0.0751 & 0.1060 & 0.1066 & 0.1288 & 0.1101 & 0.1756 & 0.0519 & & \\
\hline 9. B. rhabdophora (C) & 0.0785 & 0.1209 & 0.1216 & 0.1438 & 0.0995 & 0.1638 & 0.0527 & 0.0302 & \\
\hline 10. B. rhabdophora (N) & 0.0741 & 0.1227 & 0.1269 & 0.1452 & 0.0981 & 0.1652 & 0.0623 & 0.0458 & 0.0522 \\
\hline 11. B. cascajalensis & 0.1552 & 0.1793 & 0.1803 & 0.2127 & 0.1430 & 0.0558 & 0.1469 & 0.1503 & 0.1531 \\
\hline 12. B. punctifer & 0.2542 & 0.2504 & 0.2521 & 0.2894 & 0.2534 & 0.2356 & 0.2515 & 0.2486 & 0.2422 \\
\hline 13. B. hartwegi & 0.1032 & 0.1530 & 0.1579 & 0.1869 & 0.1095 & 0.1579 & 0.1155 & 0.1080 & 0.1206 \\
\hline 14. G. affinis & 0.1698 & 0.2076 & 0.2023 & 0.2431 & 0.1831 & 0.2171 & 0.1871 & 0.1835 & 0.1707 \\
\hline 15. G. sexradiata & 0.2046 & 0.2530 & 0.2546 & 0.2877 & 0.2343 & 0.2558 & 0.2390 & 0.2289 & 0.2239 \\
\hline 16. G. nicaraguensis & 0.1678 & 0.2142 & 0.2155 & 0.2492 & 0.1952 & 0.2004 & 0.1709 & 0.1730 & 0.1717 \\
\hline 17. Belonesox & 0.2174 & 0.2560 & 0.2576 & 0.2899 & 0.1957 & 0.2082 & 0.2342 & 0.2558 & 0.2419 \\
\hline 18. X. malinche & 0.1560 & 0.2073 & 0.2127 & 0.2344 & 0.1708 & 0.1997 & 0.1674 & 0.1933 & 0.1889 \\
\hline
\end{tabular}

Donoghue, 1989; Klassen et al., 1991). The log of 0.567 falls above the regression fitted to number of taxa suggesting that our data set is phylogenetically informative.

Branches of nonsignificant lengths are collapsed in the resultant ML tree (Fig. 2). One polytomy includes the three specimens of $B$. episcopi. The other unresolved node is at the base of the tree. The relationships among Xiphophorus, the genus Brachyrhaphis, and Belonesox + Gambusia remain unclear in this analysis. The topology of the rest of the tree is in agreement with that of the MP analysis.

A Kimura two-parameter distance matrix was used in the NJ analysis (Table 1). The resultant tree (Fig. 3) differs from the MP and ML analyses in that the relationship between the designated outgroup and Belonesox to Gambusia + Brachyrhaphis was not resolved; the relationships between the three specimens of $B$. episcopi are supported (bootstrap $=100$ ), but the two specimens from Barro Colorado Island do not fall out as each other's closest relative; and $G$. $n i$ caraguensis is most closely related to $G$. sexradiata instead of G. affinis as in both of the other analyses. Otherwise, the topology of the NJ tree matches those of the other two analyses.

The central and southern populations of $B$. rhabdophora were more closely related to each other than either was to the northern Guanacaste population in all three analyses (MP: bootstrap $=42$, DI $=1$; ML: $P<0.01$; NJ: bootstrap $=78$ ). All three analyses support a $B$. rosen $i+$ B. terrabensis clade (MP: bootstrap $=69$, DI $=$ 2; ML: $P<0.01$; NJ: bootstrap $=78$ ), a $B$. parismina $+B$. cascajalensis clade (MP: bootstrap $=$ 100, DI $=5+$; ML: $P<0.01$; NJ: bootstrap $=$
100), a Brachyrhaphis clade (MP: bootstrap $=49$, $\mathrm{DI}=3$; ML: $P<0.01$; NJ: bootstrap $=80$ ), and a Gambusia clade (MP: bootstrap $=99, \mathrm{DI}=5+$; ML: $P<0.01$; NJ: bootstrap $=100$ ).

\section{DISCUSSION}

Monophyly of the genera Brachyrhaphis and Gambusia is well supported by our data. The monophyly of the tribe Gambusini with respect to the outgroup taxon, $X$. malinche, is weakly supported and remains somewhat uncertain (Figs. 1-3). This finding is consistent with recent evaluations of cytochrome $b$ as a molecular marker (Graybeal, 1993; Meyer, 1994). Graybeal (1993), in particular, found that cytochrome $b$ was useful as a phylogenetic marker at the level of species divergences in bufonid frogs. Bootstrap values decrease the more internal the node. This is evidence that, for these fish as for other taxa, cytochrome $b$ is most helpful in resolving shallow divergences. A more slowly evolving gene, such as the $16 \mathrm{~S}$ ribosomal gene, may allow more robust resolution of the internal nodes in future studies (Meyer and Lydeard, 1993; Meyer, 1994).

All results support the monophyly of Brachyrhaphis and Gambusia. The MP and ML trees are consistent with Rauchenberger's (1989) placement of $G$. affinis and G. sexradiata as sister taxa with respect to $G$. nicaraguensis. Lydeard et al. (1995) recently reconstructed the phylogeny of 24 species of Gambusia using the same part of the gene as used in this study. Their analysis also failed to resolve the relationships among these three distantly related species. Our data weakly 
TABle 1. EXTended.

\begin{tabular}{|c|c|c|c|c|c|c|c|c|}
\hline & 10 & 11 & 12 & 13 & 14 & 15 & 16 & 17 \\
\hline \multirow{2}{*}{\multicolumn{9}{|c|}{$\begin{array}{l}\text { 1. B. roseni } \\
\text { 2. B. episcoti (BI) }\end{array}$}} \\
\hline \multirow{2}{*}{\multicolumn{9}{|c|}{$\begin{array}{l}\text { 2. B. epsscopn (B1) } \\
\text { 3. B. episcopi (B2) }\end{array}$}} \\
\hline & & & & & & & & \\
\hline \multicolumn{9}{|l|}{ 4. B. episcopi (M) } \\
\hline \multicolumn{9}{|l|}{ 5. B. holdridgei } \\
\hline \multicolumn{9}{|l|}{ 6. B. parismina } \\
\hline \multirow{2}{*}{\multicolumn{9}{|c|}{$\begin{array}{l}\text { 7. B. terrabensis } \\
\text { 8. B. }\end{array}$}} \\
\hline \multirow{2}{*}{\multicolumn{9}{|c|}{ 9. B. rhabdophora (C) }} \\
\hline & & & & & & & & \\
\hline \multicolumn{9}{|l|}{ 10. B. rhabdophora (N) } \\
\hline 11. B. cascajalensis & 0.1632 & & & & & & & \\
\hline 12. B. punclifer & 0.2525 & 0.2304 & & & & & & \\
\hline 13. B. hartwegi & 0.1179 & 0.1496 & 0.2494 & & & & & \\
\hline 14. G. affinis & 0.1683 & 0.1999 & 0.3027 & 0.1859 & & & & \\
\hline 15. G. sexradiata & 0.2164 & 0.2462 & 0.3664 & 0.2258 & 0.1279 & & & \\
\hline 16. G. nicaraguensis & 0.1865 & 0.1970 & 0.2577 & 0.1770 & 0.0968 & 0.1166 & & \\
\hline 17. Belonesox & 0.2500 & 0.2161 & 0.3056 & 0.1938 & 0.2076 & 0.2303 & 0.1848 & \\
\hline 18. X. malinche & 0.1700 & 0.2011 & 0.3072 & 0.1852 & 0.1770 & 0.2363 & 0.1932 & 0.1876 \\
\hline
\end{tabular}

support Rauchenberger's (1989) hypothesis that Gambusia and Belonesox are sister taxa.

The relationship between $B$. rosen $i$ and $B$. terrabensis is convincingly supported. This corroborates our assessment that $B$. rosen $i$ is a member of the deep-bodied clade. The relationships between B. episcopi, B. holdridgei, B. rhabdophora, and $B$. rosen $i+B$. terrabensis, on the other hand, still seem somewhat unresolved (Figs. 1-3). The monophyly of the clade that includes all of these deep-bodied species when compared with other nodes within the tree has some support (Figs. 1-3). Brachyrhaphis hartwegi is basal to this clade. It is not, however, most closely related to $B$. terrabensis as was hypothesized by Rosen and Bailey (1963). The monophyly of the $B$. parismina $+B$. cascajalensis clade (slim-bodied) is strongly supported. These molecular phylogenetic results agree with Rosen and Bailey's (1963) identification of a slim- and deep-bodied clade within this genus.

The data do not support or refute Bussing's claims (1988) that B. cascajalensis and B. parismina are the same species or that $B$. rhabdophora deserves revision at the species level. The analyses would have refuted the first claim and supported the second only if the species or populations had turned out to be paraphyletic and not monophyletic.

The data are, however, suggestive with respect to the second claim. The percent-sequence differences between the $B$. rhabdophora populations is higher than those for $B$. episcopi; B. episcopi from the Rio Mendoza shows a maximum of 2.98\% difference with respect to conspecifics from Barro Colorado Island (Table 1). The northern B. rhabdophora, when compared with southern and central populations, showed differences of $4.58 \%$ and $5.22 \%$, respectively. The minimum difference between sequences that resulted among species was $5.19 \%$ for southern B. rhabdophora and B. terrabensis (Table 1). This suggests that the central and southern populations, which exhibited a $3.02 \%$ sequence difference between one another, may be different with respect to the northern $B$. rhabdophora, as Bussing (1988) hypothesized. A more complete phylogeographic analysis is necessary to resolve this issue.

The phylogenetic trees reported here will facilitate the study of the evolution of the novel behavioral and morphological traits described above. Studies in progress, specifically, focus on the adaptive significance of anal-fin coloration and morphological elaboration. The relationship among sister taxa having different character states is particularly informative to the interpretation of these data. Preliminary results were used in defining the most meaningful taxa for these studies. The distribution of the resultant morphological and behavioral characters on the phylogeny has allowed us (CLM and GWB, unpubl.) to hypothesize the function of these novel features.

Phylogenetic approaches to behavior, morphology, and ecology can take us beyond plausibility arguments by providing refutable hypotheses of evolutionary change in the characters of interest (e.g., Meyer et al., 1994). Phylogenetic trees are necessary for testing these evolutionary hypotheses (Brooks and McLennan, 1991). They can be used to guide research, interpret preliminary data, reveal the need for certain kinds of comparative data or 


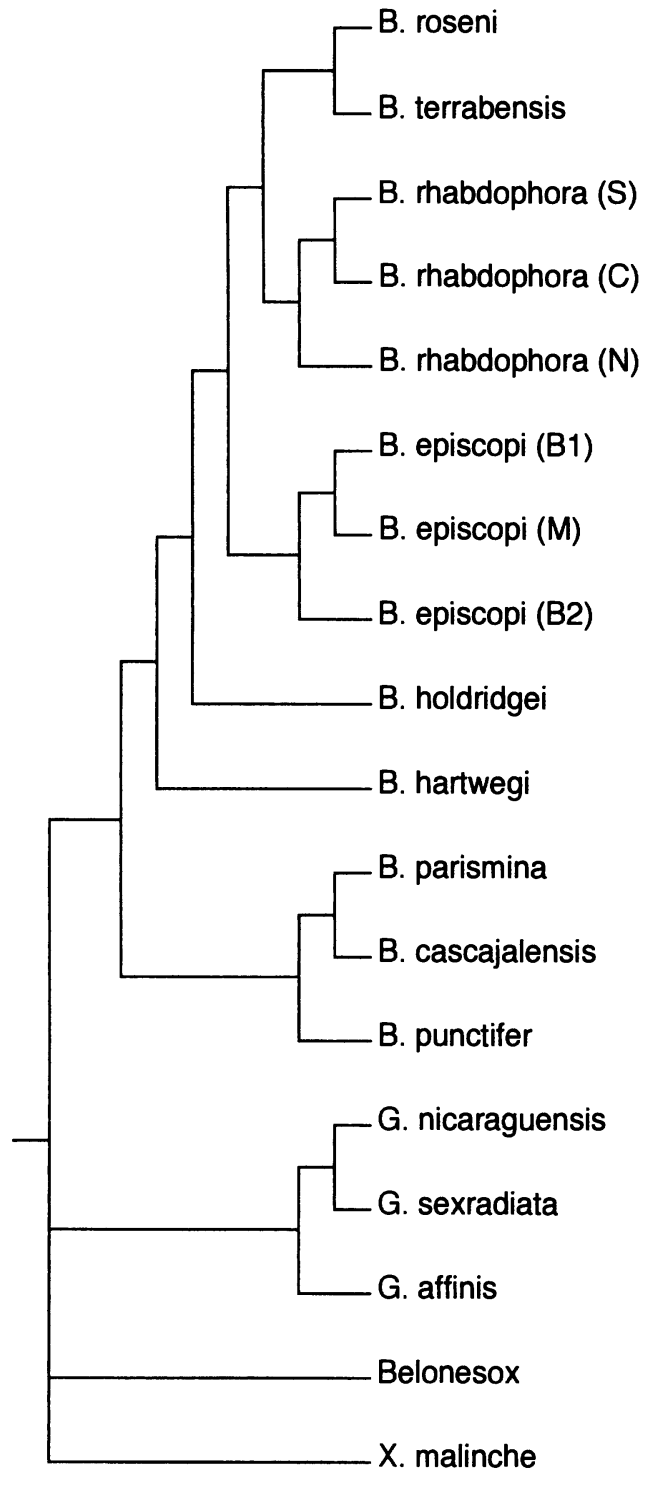

Fig. 3. Neighbor-joining result. Tree generated in PHYLIP (Felsenstein, 1989). See Materials and Methods section for details. Specimens of Brachyrhaphis episcopi from Barro Colorado Island, Panama, are denoted B1 and B2. The specimen from the Rio Mendoza is labeled M. Specimens of B. rhabdophora from the southern, central, and northern parts of Costa Rica are labeled S, C, and N, respectively.

experiments, and test evolutionary hypotheses once these data have been gathered (Brooks and McLennan, 1991).

\section{ACKNOWLEDGMENTS}

C. Orrego provided training and technical support along with $\mathrm{K}$. Le and S. Pak to CLM. K. Le aided in gathering data. J. L. Patton provid- ed equipment, laboratory resources and space. R. McKeand, M. C. Belk, S. Sung, and A. Basolo provided specimens. Collecting trips and laboratory work by CLM were supported by the Patricia Roberts Harris Fellowship, a Smithsonian 10-week graduate student fellowship, a Raney Award from the American Society of Ichthyologists and Herpetologists, National Science Foundation Grant 910852 to GWB, the Graduate Division (UCB), the Department of Integrative Biology, and Museum of Vertebrate Zoology. Comments on an early version of the manuscript were kindly made by E. Jockusch.

This work received partial support by grants from the National Science Foundation to AM (BSR-9107838 and BSR-9119867) and from a collaboration grant with the Max-Planck-Institut für Biology in Tübingen from the Max-Planck Society, Germany. This publication was prepared during AM's tenure as Miller Visiting Research Professor at the University of California at Berkeley. The support of the Miller Institute and the hospitality of the Museum of Vertebrate Zoology and the Departments of Integrative Biology and Molecular and Cell Biology are gratefully acknowledged. D. Reznick and an anonymous reviewer provided comments that allowed us to greatly improve the manuscript.

\section{Literature Cited}

Basolo, A. L. 1995. Phylogenetic evidence for the role of a pre-existing bias in sexual selection. Proc. R. Soc. Lond. B Biol. Sci. 259:307-311.

Brooks, D. R., AND D. A. McLennan. 1991. Phylogeny, ecology and behavior: a research program in comparative biology. Univ. of Chicago Press, Chicago.

Bussing, W. A. 1966. New species and new records of Costa Rican freshwater fishes with a tentative list of species. Rev. Biol. Trop. 14:205-249.

. 1988. A new fish, Brachyrhaphis roseni (Poeciliidae) from Costa Rica and Panama. Ibid. 36:8187.

ENDLER, J. A. 1995. Multiple-trait coevolution and environmental gradients in guppies. Trends Ecol. Evol. 10:22-29.

Felsenstein, J. 1985. Evolutionary trees from DNA sequences: a maximum likelihood approach. J. Mol. Evol. 17:368-376.

- 1989. PHYLIP-phylogenetic inference package. Cladistics 5:164-166.

GRAYBEAL, A. 1993. The phylogenetic utility of cytochrome $b$. lessons from Bufonid frogs. Mol. Phyl. Evol. 2:256-269.

Houde, A. E., AND J. A. Endler. 1990. Correlated evolution of female mating preferences and male color pattern in the guppy Poecilia reticulata. Science (Wash.) 248:1405-1408.

HUBBS, C. L. 1926. Studies of the fishes of the order 
Cyprinodontes. Misc. Publ. Mus. Zool. Univ. Mich. 6:1-87.

KIMURA, M. 1980. A simple method for estimating evolutionary rates of base substitutions through comparative studies of nucleotide sequences. $\mathrm{J}$. Mol. Evol. 16:111-120.

KLASSEN, G. J., R. D. MoOI, AND A. LOCKE. 1991. Consistency indices and random data. Syst. Zool. 40: 446-457.

Kocher, T. D., W. K. Thomas, A. Meyer, S. V. EDWARDS, S. PAABo, F. X. VILLABLANCA, AND A. C. WILSON. 1989. Dynamics of mitochondrial DNA evolution in animals: amplification and sequencing with conserved primers. Proc. Nat. Acad. Sci. 86: 6196-6200.

LYDEARD, C., M. C. WOOTEN, AND A. MEYer. 1995. Cytochrome $b$ sequence variation and a molecular phylogeny of the live-bearing fish genus Gambusia (Cyprinodontiformes: Poeciliidae). Can. J. Zool. 73: 213-227.

MeEK, S. E. 1912. New species of fishes form Costa Rica. Publ. Field Columbian Mus., Zool. Ser. 10:6975.

- AND S. F. Hildebrand. 1913. New species of fish from Panama. Publ. Field Mus. Nat. Hist., Zool. Ser. 10:77-91.

MEYER, A. 1994. Shortcomings of cytochrome $b$ gene as a molecular marker. TREE 9:278-280.

- AND C. LYDEARD. 1993. The evolution of copulatory organs, internal fertilization, placentae, and viviparity of killifishes (Cyprinodontiformes) inferred from a DNA phylogeny of tyrosine kinase gene X-src. Proc. R. Soc. (Lond.) 254 Ser. B:153162.

MORRIS, M. R., M. MUSSEL, AND M. J. RYAN. 1995. Vertical bars on male Xiphophorus multilineatus: a signal that deters rival males. Behav. Ecol. 6:274-279.

RAUCHENBERGER, M. 1989. Systematics and biogeography of the genus Gambusia (Cyprinodontiformes: Poeciliidae). Am. Mus. Novit. 2951:1-74.

Regan, C. T. 1907. Diagnoses of new Central Amer- ican freshwater fishes of the families Cyprinodontidae and Mugilidae. Ann. Mag. Nat. Hist. 19, Ser. 7:64-66.

1908. A collection of freshwater fishes made by Mr. C. F. Underwood in Costa Rica. Mag. Nat. Hist. 2, Ser. 8:455-464.

. 1913. A revision of the cyprinodont fishes of the subfamily Poeciliinae. Proc. Zool. Soc. Lond. 11:977-1018.

Rosen, D. E., AND R. M. Bailey. 1963. The poeciliid fishes (Cyprinodontiformes), their structure, zoogeography, and systematics. Bull. Am. Mus. Nat. Hist. 126:1-176.

SAITOU, N., AND M. Nel. 1987. The neighbor-joining method: a new method for reconstructing phylogenetic trees. Mol. Biol. Evol. 4:406-425.

Sanderson, M. J., and M. J. Donoghue. 1989. Patterns of variation in levels of homoplasy. Evolution 43:1781-1795.

Smith, M. F., and J. L. Patton. 1993. The diversification of South American murid rodents: evidence from mitochondrial DNA sequence data for the akondontine tribe. Biol. J. Linn. Soc. 50:149-177.

STEINDACHNER, F. 1878. Ichthyologische Beitrage (VI). Sitzber. K. Akad. Wiss Wien, Math. Nat. Cl. 77: 379-392.

Walsh, P. S., D. A. MetzGer, and R. Higuchi. 1991. Chelex 100 as a medium from simple extraction of DNA for PCR-based typing from forensic material. BioTechniques 10:506-513.

(CLM, GWB) DEPaRTMENT OF INTEgRaTIVE BIOLOGY AND MUSEUM OF VERTEBRATE ZOOLOGY, University of California, Berkeley, CaliFORNIA 94720; AND (AM) DEPARTMENT OF Ecology and Evolution and Program in Genetics, State University OF New York at StONy Brook, Stony Brook, New YORK 11794-5245. Send reprint requests to CLM. Submitted: 30 April 1996. Accepted: 5 Sept. 1996. Section editor: R. Winterbottom. 